International Journal of Instruction e-ISSN: 1308-1470 • www.e-iji.net

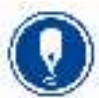

October $2020 \bullet$ Vol.13, No.4

p-ISSN: 1694-609X

pp. $815-832$

Received: $28 / 07 / 2019$

Revision: $15 / 05 / 2020$

Accepted: 06/06/2020

OnlineFirst:29/08/2020

\title{
L1 Textual Glosses and Word Repetition: Facilitative Interventions for Incidental Vocabulary Acquisition
}

\author{
Mohammad Hassan AlRamadhan
}

Lecturer at King Faisal University, Al Ahsa, Saudi Arabia, malramadhan@kfu.edu.sa

In the field of second language acquisition (SLA), a large base of research has shown the great influence of L2 reading on L2 vocabulary acquisition. Nevertheless, researchers have also found that acquiring new vocabulary happens rather gradually and in small amounts. Without altering the incidental nature of vocabulary acquisition through reading, this study aims at providing facilitative reading interventions in the form of L1 textual glosses and word frequency of occurrence (word repetition) to promote vocabulary growth. A total of 146 intermediate-level students from a local school were divided into two main groups: treatment and control groups. The treatment group was split into three sub-groups; a gloss (G) group which received only L1 (Arabic) textual glosses, a repetition (R) group which received only repetitions of the target words, and a gloss/repetition $(\mathrm{G}+\mathrm{R})$ group which received both $\mathrm{L} 1$ textual glosses and repetitions of the target words. The control group received typical instruction. For assessment purposes, I used a set of 10 tests of binary distinctions, receptive and productive measures to measure vocabulary growth. The results indicated that students in the G, R, and $\mathrm{G}+\mathrm{R}$ group outperformed their counterparts in the control group. Moreover, it appeared that glossing alone was more effective than word repetition alone and that both glossing and repetition together were more efficient than glossing alone.

Keywords: textual gloss, word repetition, L2 reading, reading comprehension, language learning, vocabulary acquisition, incidental learning

\section{INTRODUCTION}

This study aims at developing learners' interlanguage vocabulary by offering word repetition and textual glosses in the learners' native language. Despite the effective impact of L2 reading on vocabulary acquisition, studies (Zahar, Cobb and Spada, 2001; Horst, Cobb and Meara, 1998; Pitts, White and Krashen, 1989; Day, Omura and Hiramatsu, 1991) in the history of L2 reading have revealed that reading alone is not sufficient to guarantee the acquisition of an exuberant amount of new lexical items incidentally. It was apparent from the results of these studies that students could accurately acquire limited vocabulary as a result of reading lengthy texts.

Citation: AlRamadhan, M. H. (2020). L1 Textual Glosses and Word Repetition: Facilitative Interventions for Incidental Vocabulary Acquisition. International Journal of Instruction, 13(4), 815832. https://doi.org/10.29333/iji.2020.13450a 
The significance of this study stems from two grounds. First is the centrality of this applied linguistic area, namely vocabulary acquisition, which received a growth of interest over the past years (Zahar, Cobb and Spada, 2001; Meara, 1980). Second, many Saudi EFL students, both school-age and undergraduate students, suffer from a lack of the basic threshold vocabulary (Al-Shabab, 2012; Al-Shiekh Mubarak, 2009) that is necessary for the comprehension of $95 \%$ of any text (Nation, 2006).

In the literature of L2 vocabulary learning, few studies have addressed the impact of word repetition together with textual glosses side by side on word gains. Given that, this study offers an in-depth investigation of the two variables and attempts to answer the following questions:

- Do L1 textual glosses facilitate the short-term incidental vocabulary acquisition of new lexical items as opposed to the no gloss condition?

- Do L2 word repetitions facilitate the short-term incidental vocabulary acquisition of new lexical items as opposed to the no repetition condition?

- Do the integration of L1 textual glosses and word repetition together facilitate the short-term incidental vocabulary acquisition of new lexical items as opposed to the $\mathrm{L} 1$ textual gloss condition and word repetition condition alone?

I hypothesized that these two reading interventions, namely L1 textual glosses and word repetition, are significant in reading classes. They offer an enhanced learning experience of new vocabulary and an opportunity for a blended learning environment where students can benefit from both intentional and incidental learning.

\section{Incidental and Intentional Learning}

The theory of incidental and intentional learning is rooted in the earliest works of wellknown psychologists such as Thorndike (1908) and Siebert (1930). It was not until the 1980s that these notions circulated amongst scholars in the field of SLA. However, the distinction between incidental and intentional learning is not clear-cut and both have not been well defined in the literature of second language acquisition. De Ridder (2003) claimed that "no strong theoretical definition of incidental vocabulary learning has yet been proposed. It is often discussed as the counterpart of intentional vocabulary learning" (p.16). Nevertheless, for some researchers like Ellis (1999) and Hulstijn (2003), the subtle distinction between both types of learning lies in the "attention" students place during the reading activity. Hulstijn (2003) argued that both incidental and intentional vocabulary learning differ in terms of the degree of "attention" each type receives. He concluded, "the attention is deliberately directed to committing new information to memory in the case of intentional learning, whereas the involvement of attention is not deliberately geared toward an articulated learning goal in the case of incidental learning" (p.361).

In the literature of SLA, there seems to be less consensus among researchers as to whether vocabulary learning should be approached in an incidental or intentional fashion. Those who are in favor of incidental vocabulary learning (Krashen, 1989; Nagy, Herman and Anderson, 1985; Nagy and Herman, 1987) always justify their 
position on the ground that incidental learning usually yields better results as opposed to intentional learning. Krashen (1989) attributes such privilege to the availability of a context that enriches word learning both syntactically and semantically, a feature that is absent in the intentional learning of words from a wordlist. Similarly, Nagy, Herman, and Anderson (1985) maintain that intentional vocabulary learning does not necessarily entail much progression in either reading or vocabulary size. They claim that while intentional vocabulary learning through instruction is feasible for a small set of words, incidental vocabulary learning is more effective if we wish learners or readers to acquire "several thousand words per year" (p.41).

On the contrary, other researchers (Hulstijn, 1992; Hulstijn, Hollander and Greidanus 1996; Stahl and Fairbanks, 1986) do not deny the effectiveness of incidental learning, but seem to hold a contrasting stand in that intentional vocabulary learning is conductive and useful, and usually result in retention of meaning, especially with beginner learners. Hulstijn et al (1996) maintain that despite the efficacy of the vocabulary learned incidentally, the number of words is often low, and that there is a need for enhancing incidental learning of new vocabulary. They recommended that learners must engage in elaborating activities which help them pay attention to the new words to be learned. Moreover, they suggested that both syllabus designers and practitioners should make available a list of important words to learn besides the ones learned incidentally.

According to Paribakht and Wesche (1999), a vast line of L1 and L2 research on language development advocates the idea that the natural setting of learning new lexical items is when students engage in meaning-focused reading activities. That is, as students intend to comprehend the meaning of a reading passage, they normally end up learning new words incidentally as a result of their endeavor to achieve comprehension. Krashen, 1989; Nagy, Herman and Anderson, 1985; Nagy and Herman, 1987 demonstrate that incidental learning usually yields better results when compared to intentional learning. This study takes both types of learning into consideration and suggested an environment of blended learning. This type of blended learning is realized by offering textual glosses and word repetition as reading interventions in reading classes.

\section{L1 Textual Glosses}

Glosses, also identified as annotations, are sometimes used in L2 reading materials in order to explain an unknown word or concept. L2 reading texts can be modified for this purpose to introduce glosses in readers' native language. Watanabe (1997) argued that such modifications to L2 reading texts are necessary in order to increase readers' level of comprehension. He noted, "input modification has been an important area in second language research. The motivation behind this has been the assumption that input must be comprehensible to become intake" (P.287). Moreover, glossing is seen as a semantic intervention that helps students link the meaning to the form of the L2 word (Rott, Williams and Cameron, 2002; Rott, 2005).

The need to use glosses arises from the fact that although reading results in the acquisition of vocabulary incidentally, the process is seen to be slow (Hulstijn, Hollander and Greidanus, 1996; Jacobs, Dufon and Fong, 1994; Read, 2004). Hulstijn, 
Hollander, and Greidanus (1996) examined the effects of L1 textual glosses, along with other semantic interventions, on the task of learning vocabulary incidentally. They conducted this study on 78 advanced Dutch students learning French as an L2. Students had to read a story called "Menuet" of 1,300 words under three conditions: Marginal L1 glosses, dictionary use, and a controlled text. The text had 16 target low-frequency words, which were pre-tested to ascertain their unfamiliarity. They found that students in the gloss and dictionary conditions outperformed those who received no gloss. However, the results also showed that students in the gloss group scored twice their colleagues who used a dictionary .

Watanabe (1997) used multiple-gloss types to investigate the relevant value of glosses on incidental vocabulary learning. He modified the text to test three types of glosses: single marginal, appositive, and multiple glosses, plus the control condition. The marginal glosses were provided at the right of the page, the appositive glosses directly followed the target words inside the text, and the multiple-choice glosses were offered with two options at the right of the text. A total of 213 Japanese students of English were assigned to read an article of 500 words. Sixteen words were chosen as target words. The results showed that students who received both single marginal and multiple-choice glosses scored higher than those who received appositive glosses and no glosses. Moreover, the results suggested that a single marginal (textual) gloss was more effective than the multiple-gloss type.

Al-Jabri (2009) has addressed the issue of the significance of L1 and L2 glosses. He ran his study on 90 Saudi university students majoring in English as a foreign language. The participants were randomly assigned to three different groups: L1 gloss group, L2 gloss group, and no gloss group. The aim of the researcher was to assess which gloss type was more effective in the task of reading comprehension and recalling of ideas. The participants had to read a text of 470 words, 19 of which were selected for glossing. The text was modified to include the L1 and L2 gloss conditions. Two tests were given after the participants had completed the reading activity; a comprehension test and a recall test of ideas. The analysis of the results indicated that students who received both L1 and L2 gloss groups had a more significant difference in their performance than those in the no-gloss group in the comprehension as well as recall tasks. More interestingly, the participants who received L1 glosses scored higher than their counterparts who received L2 glosses. This also applied to the recall test of ideas. Students in the L1 gloss group were able to recall more ideas than those in the L2 gloss group.

\section{Word Repetition}

Saragi, Nation, and Meister's (1978) study was one of the very early works that intended to investigate the impact of word frequency of occurrence on incidental vocabulary acquisition. They examined the incidental acquisition of unknown Russian slang words through reading. During the experiment, learners were not made aware of the purpose and were not asked to memorize or recall any word of the text. The results suggested that words occurring more than once tended to have a higher possibility of acquisition, although the number of encounters was not conclusive. The analysis illustrated that there is 0.34 correlation size between word repetition and students' gain. Saragi et al found 
that $15 \%$ of the learners were able to pick up a word that occurred nine times, and $40 \%$ of them were able to learn a word that was repeated forty-two times. The researchers have suggested that ten or more encounters of a word can lead to its acquisition.

In the glossing study reviewed above by Hulstijn, Hollander, and Greidanus (1996), the researchers investigated the effect of word repetition as well. They assumed that words appearing more frequently are likely to be acquired first when they are provided along with glosses. A total of 78 Dutch students of French as a foreign language were tested on a reading passage. Sixteen target words were selected for the experiment. Two groups of 8 words were constructed. One group contained words that occurred once and the other one contained words that appeared three times. Learners were then tested on all 16 words through a receptive test. Three post-tests were administered. The results of the study confirmed the strong effect of frequency of occurrence on word gains. It was found that students attained those words repeated three times more than those which occurred only once .

Another study by Horst, Cobb, and Meara (1998) examined the effect of word repetition on learning new words. They conducted their study on 34 Omani participants who were learning English as a foreign language. They were required to finish reading a 21,232word book in ten days. A total of 23 target words were selected to be the target words for investigation. The results suggested that words repeated eight or more times had higher predictability of acquisition than those occurring only once or twice. Horst et al (1998) suggested that other factors would intervene in the acquisition of words that were repeated less than eight times. They found that word frequency (frequency bands/levels) was not that effective. This entails that high-frequency words do not necessarily have a higher tendency to be acquired first and low-frequency words second. Furthermore, the results showed that other factors apart from repetition, such as pictures and the part of speech, were highly effective in word learning. Both concrete nouns and words that were accompanied by pictures like the two words grave and magistrate, were repeated five times yet were highly attained by students.

Similarly, Rott (1999) looked into the effect of word repetition on the incidental learning of new words through reading. She conducted a study on 67 learners of German as a foreign language. Twelve words were selected as target words that belonged to everyday life actions. Of the 12 words, some received 2 repetitions, 4 repetitions, and 6 repetitions. The aim was to assess both the acquisition as well as the retention of those target words through a receptive and a productive test. The results showed that words that received six encounters were better acquired and retained than the ones with two and four encounters. Interestingly, the analysis of the results also revealed that there was no significant difference between words which were repeated two or four times. However, Rott concluded that the overall results suggest the positive impact of word repetition on acquiring new words while reading.

In the same vein, Zahar, Cobb and Spada (2001) examined the benefit of the frequency of occurrence on learning new vocabulary incidentally. They conducted a study on 144 French ESL learners. The participants were required to read a short novel of 2,383 words, of which 30 words were chosen as target words. The target word occurrences 
ranged from one to fifteen times. The results of their study established a significant correlation size between the frequency of occurrence and word gain at the level of 0.36. However, Zahar et al (2001) concluded that the effect of word repetition is very useful with low-level learners and that this effect is likely to decay as students' level grows.

\section{METHOD}

\section{Participants}

The participants in this study were one hundred and forty-six male third-grade intermediate students. They were all native speakers of Arabic between 15 to 17 years. All the participants have studied English for two years and have completed two gradedreader English textbooks prior to this experiment. Students were assigned to two groups: a treatment group and a control group. The treatment group was divided into three subgroups: a glossing group $(\mathrm{G})$, a repetition group (R), a gloss-and-repetition group $(\mathrm{G}+\mathrm{R})$. Each group was an entire class. The G group (22 students) received passages with glosses only; the $\mathrm{R}$ group ( 25 students) received passages that had word repetitions only; the $\mathrm{G}+\mathrm{R}$ group (30 students) received passages designed to have both glosses and word repetitions together. The second main group was a control group. Students in this group were not exposed to any form of the treatment. They studied the same textbook students in the treatment group had, received the same amount of instruction and took the same classroom activities.

\section{Instruments}

\section{Nation's vocabulary levels test}

In this study, Nation's Levels Test (VLT) was assigned for students to complete in order to measure their vocabulary proficiency and to see at which frequency band/level they are competent. In particular, students had to do the first three levels in sequence; the first, second and third (recognition) 1,000 words. The researcher assumed that the participants' vocabulary knowledge would not exceed that of the second level. However, if the participants successfully managed to do up to $80 \%$ at each level, the next level $(4,000)$ was to be assigned. The test was assigned one day after students had finished the pretest. The students were allowed one class session to complete the VLT. Moreover, the researcher provided instructions in the participants' L1 to demonstrate their task.

\section{Pretest}

In this study, the pretest is a pen-and-paper pretest designed by the researcher. It was assigned to students one week prior to the experiment. In the pretest, students were required to supplement the meaning of the target items as well as the additional distractors in their native language. They were also instructed to supplement an English synonym for each word if possible. The participants were allowed 30 minutes to complete the 20 items. The 20 words were tested to examine familiarity. Results of the pretest showed that three words of the target items were known to some participants and most of the distractors were familiar as expected. The researcher had to ensure that no single item was recognized. Therefore, another three words were selected to replace the known ones. They were unknown to all students. Furthermore, any answer that was 
close to the meaning of a target item was deemed to be the simplest format of recognition and consequently required the substitution of that target word.

\section{Reading texts}

The reading materials used in this experiment were selected from the same textbook students were using as their curriculum. The textbook was a graded reader titled "say it in English". Three reading passages were considered for this experiment. They were selected from the first three chapters successively. The reading passages were tailored to suit each of the three reading interventions. That is, students in the $\mathrm{G}$ group received passages with glosses only, students in the $\mathrm{R}$ group received passages with word repetitions only, and students in the $\mathrm{G}+\mathrm{R}$ group received both glosses and word repetitions, while students in the $\mathrm{C}$ group received none of the conditions.

The $\mathrm{LIX}^{1}$ readability software was run over the three passages in order to determine the difficulty and readability of the three texts. The first two passages were classified as easy and the third passage was classified as standard according to the LIX values of difficulty. Table 1 indicates the LIX values of each reading passage and its level of difficulty.

Table 1

The LIX Values of the Three Texts and Their Level of Difficulty

\begin{tabular}{lll}
\hline Passage title & The LIX value & Level of difficulty \\
\hline Dictionary Skills & 28 & Easy \\
Are you a planner? & 31 & Easy \\
Eiffel Tower & 44 & Standard \\
\hline
\end{tabular}

\section{Target words}

Ten target words were selected for the experiment from the third band in the frequency list. All of the items were pre-tested to ensure their unfamiliarity with all participants. The target items were textually glossed in learners' L1 (Arabic). They appeared in each reading passage to guarantee that spaced repetition was achieved. In addition, another 10 words (non-target items) were glossed. The purpose was primarily to divert students' attention from the target glossed items for if the target items had been the only glossed words, students might pay due attention to them. The other 10 glossed words were part of the three reading passages. However, unlike the target items, the additional glossed distractors received no repetition across the different passages. Five of the distractors were nouns, four were verbs and one was adjective. Following Karp (2002), the selected additional glossed items were more likely to be known to participants so that they would not feel discomforted or discouraged by the heavy burden of the unknown words.

More significantly, the researcher had to make sure that no more than one target word was used in one sentence in order to avoid lexical density. In addition, the target words

\footnotetext{
${ }^{1}$ LIX is a readability measure developed by the Danish Carl-Hugo Björnsson (1968). LIX is a short form of the word Lasbarhetsindex.
} 
were of two syntactic categories; nouns and verbs. They form the most frequent syntactic categories that make up the majority of the English discourse. Words that had a dual syntactic function, such as the word benefit, were fixed only to one syntactic class and were never changed through the different contexts.

\section{Posttests}

The posttests were devised according to Nation's (2001) framework of word knowledge. Since the framework is multi-componential, there is no one complete test that can measure all aspects of vocabulary knowledge at once. This entails that in order to assess learners' vocabulary acquisition properly, different tests are needed to measure the different aspects of word knowledge. However, Nation's framework was adapted to suit the current experiment. Not all subtypes of word knowledge were tested. This is because learners are still at the intermediate level and that some subtypes of knowledge are beyond students' current linguistic level and are still early for learners to learn. Such advanced aspects of word knowledge are believed to be acquired through multiple exposures to the same words at some advanced levels later. Another reason is that Nation's framework is an idealistic theoretical description of what is involved in knowing a word. That is, not every native speaker does really know all of these knowledge aspects of the total words they possess in their mental lexicon. Read (1993) noted that "native speakers have only partial knowledge of the meaning of many of the words that they know" (p.357). The case becomes more complex with ESL/EFL learners. Thus, in terms of testing, it would logically be difficult to measure every single aspect of word knowledge for a large set of items. Read (2000) maintained that "when we look at Nation's table from an assessment perspective, it appears rather daunting" (p.27). Table 2 presents a summary of the selected aspects of testing in this experiment.

Table 2

The Selected Aspects of Word Knowledge from Nation's Framework for This Study

\begin{tabular}{|c|c|c|c|}
\hline $\begin{array}{l}\text { Aspect of } \\
\text { knowledge }\end{array}$ & $\begin{array}{l}\text { Measured knowledge } \\
\text { type }\end{array}$ & $\begin{array}{l}\text { Receptive/ productive } \\
\text { knowledge }\end{array}$ & Type of test \\
\hline \multirow[t]{4}{*}{ Form } & \multirow[t]{2}{*}{ Spoken } & Productive & Oral interview \\
\hline & & Receptive & Multiple-choice \\
\hline & \multirow[t]{2}{*}{ Written } & Productive & Dictation \\
\hline & & Receptive & Multiple-choice \\
\hline \multirow[t]{4}{*}{ Meaning } & \multirow[t]{2}{*}{ Form and meaning } & Productive & Definition-supply \\
\hline & & Receptive & Multiple-choice \\
\hline & \multirow[t]{2}{*}{ Association } & Productive & Free WA task* \\
\hline & & Receptive & Multiple-choice \\
\hline \multirow[t]{2}{*}{ Use } & \multirow[t]{2}{*}{ Grammatical functions } & Productive & Sentence construction \\
\hline & & Receptive & Multiple-choice \\
\hline
\end{tabular}

* WA= word association

\section{Data Analysis}

In order to carry out the analysis of data in this study, the Statistical Package for the Social Sciences (SPSS) version 18 for Windows was utilized. Each of the research questions addressed in the introduction was followed by some statistical analysis to 
answer the question. One-way ANOVA analyses were conducted on certain data several times. They were carried out in order to compare the performance of each treatment group against the corresponding control group. Therefore, the one-way ANOVA was run three times for each of the following: $G$ group vs. $C G$ group, $R$ group vs. CR group and $\mathrm{G}+\mathrm{R}$ group vs. $\mathrm{CG}+\mathrm{R}$ group. Moreover, another one-way ANOVA was conducted to compare the means of all treatment groups against the means of the control groups. In addition, a one-way analysis of variance (ANOVA) was used to measure the impact and the combination of both variables - glossing and repetition - on the incidental acquisition of unknown lexical items.

\section{FINDINGS}

\section{Q1. Do L1 Textual Glosses Facilitate the Short-Term Incidental Vocabulary} Acquisition of New Lexical Items as Opposed to the No Gloss Condition?

The first research question investigated the impact of L1 textual glosses as a reading intervention on the acquisition of the target items incidentally. To answer this question, data was gathered from the immediate posttests given to the participants. A one-way analysis of variance (ANOVA) was used to measure the performance of the two groups; the Gloss (G) group and the control group (CG) group, to see whether glossing would have a significant impact on word gains. Table 3.1 outlines the one-way ANOVA statistical results of both groups, and table 3.2 shows the mean scores of each group.

Table 3.1

One-way ANOVA Analysis for Immediate Vocabulary Test Scores

\begin{tabular}{llllll}
\hline & Sum of Squares & Df & Mean Square & F & Sig. \\
\hline Between Groups & 5348.579 & 1 & 5348.579 & 25.375 & .000 \\
Within Groups & 8642.026 & 41 & 210.781 & & \\
Total & 13990.605 & 42 & & & \\
\hline
\end{tabular}

Table 3.2

One-way ANOVA Analysis for Immediate Vocabulary Test Scores

\begin{tabular}{lllll}
\hline & $\mathrm{N}$ & Mean (of 100) & SD & SD. Error \\
\hline Glossing & 22 & 68.45 & 13.085 & 2.790 \\
No glossing & 21 & 46.14 & 15.885 & 3.466 \\
Total & 43 & 57.56 & 18.251 & 2.783 \\
\hline
\end{tabular}

The results revealed that there was a significant difference between the two groups. In other words, students who received L1 textual glosses performed significantly higher than their counterparts who received no glossing at all. The mean score of the Group was $68.45(\mathrm{SD}=13.085)$, while the mean score of the $\mathrm{CG}$ group was $46.14(\mathrm{SD}=15.885)$. This indicates the efficacy of adding L1 textual glosses and their positive impact on acquiring new lexical items.

Q2. Do L2 Word Repetitions Facilitate the Short-Term Incidental Vocabulary Acquisition of New Lexical Items as Opposed to the No Repetition Condition?

The second research question seeks to examine the effectiveness of word frequency of occurrence (word repetitions) as a reading intervention on acquiring the target items 
incidentally. Like the first research question, the researcher obtained data from the immediate posttests given to the participants. First, to measure the effect of word repetition, the performance of the two groups, the Repetition (R) group and the Control Group (CG), was measured through a one-way analysis of variance (ANOVA). Table 4.1 summarizes the statistical results of both groups, and table 4.2 outlines the mean scores of each group.

Table 4.1

One-way ANOVA Analysis for Immediate Vocabulary Test Scores

\begin{tabular}{llllll}
\hline & Sum of Squares & Df & Mean Square & F & Sig. \\
\hline Between Groups & 2779.511 & 1 & 2779.511 & 6.289 & .016 \\
Within Groups & 21654.998 & 49 & 441.939 & & \\
Total & 24434.510 & 50 & & & \\
\hline
\end{tabular}

Table 4.2

Statistical Analysis of the Immediate Vocabulary Test Scores by Groups

\begin{tabular}{lllll}
\hline & N & Mean (of 100) & Std. Deviation & Std. Error \\
\hline Repetition & 25 & 49.96 & 23.391 & 4.678 \\
No repetition & 26 & 35.19 & 18.465 & 3.621 \\
Total & 51 & 42.43 & 22.106 & 3.096 \\
\hline
\end{tabular}

As indicated from the above tables, it is clear that word frequency of occurrence had an impact on word gains. In other words, students in the R group who received repetitions of the target items were able to perform higher on the immediate posttests than their counterparts in the CG group who received no repetition at all. The mean score of the $\mathrm{R}$ group was $49.96(\mathrm{SD}=23.391)$, which was higher than that of the CG group 35.19 $(\mathrm{SD}=18.19)$. Further, the one-way analysis of variance (ANOVA) revealed that the difference between the two groups was also found to be significant $(F(1.49)=6.289, P$ $=.016<.05)$.

Q3. Do the Integration of L1 Textual Glosses and Word Repetition Together Facilitate the Short-Term Incidental Vocabulary Acquisition of New Lexical Items as Opposed to the L1 Textual Gloss Condition and Word Repetition Condition Alone?

The final research question was focused on the relationship of L1 textual glossing and word frequency of occurrence. It investigated the impact of merging these two independent variables side by side on the incidental acquisition of new vocabulary items. A comparison of performance on the immediate posttests was conducted between the Gloss/Repetition $(\mathrm{G}+\mathrm{R})$ group who received both variables in their experimental texts and the Control Group (CG) who had not been exposed to the former independent variables. Thus, a one-way analysis of variance (ANOVA) was employed to assess the answers on the immediate posttests to determine which of these groups performed highly better than the other. Tables 5.1 and 5.2 summarize the results of the ANOVA analysis. 
Table 5.1

One-way ANOVA Analysis for Immediate Vocabulary Test Scores

\begin{tabular}{llllll}
\hline & Sum of Squares & df & Mean Square & F & Sig. \\
\hline Between Groups & 1755.497 & 1 & 1755.497 & 7.297 & .009 \\
Within Groups & 12029.330 & 50 & 240.587 & & \\
Total & 13784.827 & 51 & & & \\
\hline
\end{tabular}

Table 5.2

Statistical Analysis of the Immediate Vocabulary Test Scores by Groups

\begin{tabular}{lllll}
\hline & $\mathrm{N}$ & Mean of (100) & Std. Deviation & Std. Error \\
\hline Glossing+Repetition & 30 & 77.53 & 17.602 & 3.214 \\
No Glossing+Repetition & 22 & 65.77 & 12.039 & 2.567 \\
Total & 52 & 72.56 & 16.441 & 2.280 \\
\hline
\end{tabular}

From the analysis shown in the preceding tables, the results showed that the two independent variables together had an impact on acquiring new vocabulary items incidentally. That is, students in the treatment $\mathrm{G}+\mathrm{R}$ group who received both $\mathrm{L} 1$ textual glosses accompanied by repetitions of the target items were able to do better on the immediate posttests than their partners in the control CG who did not receive any of the former variables. The mean score of the $\mathrm{G}+\mathrm{R}$ group was 77.53 ( $\mathrm{SD}=17.602)$, which was higher than the mean score of the CG 65.77 ( $\mathrm{SD}=12.039)$. Moreover, the one-way analysis of variance (ANOVA) demonstrated that the difference between the treatment group and the control group was highly significant $(F(1.50)=7.297, P=.009<.05)$.

\section{Analysis by Test Type}

I was also interested in finding out the relevant effect of this combination among the treatment groups by test type to assess the impact of L1 textual glosses and word frequency of occurrence on the meaning tests as well as the form and use tests. The reason was to examine the assumption that the combination of L1 textual glosses and word repetition would foster the acquisition of meaning, form and use as aspects of word knowledge successively, and that the group which received such a combination would score higher in the meaning, form and use tests. Therefore, a comparison of performance, using a one-way ANOVA, on the former three test types among the treatment groups was carried out to determine which of these groups scored higher on these tests. The ANOVA results and the mean scores of the treatment groups on the three tests are presented in Tables 6.1 and 6.2. 
Table 6.1

One-way ANOVA Analysis of the Treatment Groups for the Meaning, Form and Use Test Scores

\begin{tabular}{llllll}
\hline & Sum of Squares & df & Mean Square & F & Sig. \\
\hline Between Groups & 10555.106 & 2 & 5277.553 & 15.189 & .000 \\
Within Groups & 25711.881 & 74 & 347.458 & & \\
Total & 36266.987 & 76 & & & \\
\hline
\end{tabular}

Table 6.2

The Mean Scores of the Treatment Groups on Meaning, Form and Use Tests

\begin{tabular}{lllll}
\hline & N & Mean & Std. Deviation & Std. Error \\
\hline Glossing & 22 & 68.45 & 13.085 & 2.790 \\
Repetition & 25 & 49.96 & 23.391 & 4.678 \\
Gloss+Repetition & 30 & 77.53 & 17.602 & 3.214 \\
Total & 77 & 65.99 & 21.845 & 2.489 \\
\hline
\end{tabular}

From the above tables, it is obvious that participants in the $\mathrm{G}+\mathrm{R}$ group benefited most from the combination of the two variables side by side as opposed to their counterparts who received each variable on its own. In other words, students in the G+R group who received L1 textual glosses together with word repetition scored higher on the meaning, form and use $(\mathrm{M}=77.53, \mathrm{SD}=17.602)$, immediate posttests than the other treatment groups. Moreover, the difference between the treatment groups was found to be statistically highly significant $(F(2.74)=15.189, P=.000<.05)$.

As seen from the one-way analysis of variance (ANOVA) table, the difference between the treatment groups was deemed highly significant. Yet, such a significant difference in the mean scores is not known to which of the treatment groups it belonged. Therefore, a Tukey HSD post hoc testing procedure was employed. The results are outlined in the following Table.

Table 7

Tukey HSD Post Hoc Testing

\begin{tabular}{|c|c|c|c|c|c|c|}
\hline \multirow[t]{2}{*}{ (I) condition } & \multirow[t]{2}{*}{ (J) condition } & \multirow{2}{*}{$\begin{array}{l}\text { Mean } \\
\text { Difference (I-J) }\end{array}$} & \multirow[t]{2}{*}{ Std. Error } & \multirow[t]{2}{*}{ Sig. } & \multicolumn{2}{|c|}{$95 \%$ Confidence Interval } \\
\hline & & & & & Lower Bound & Upper Bound \\
\hline \multirow[t]{2}{*}{ Glossing } & Repetition & $18.495^{*}$ & 5.449 & .003 & 5.46 & 31.53 \\
\hline & Gloss+Repetition & $-9.079-$ & 5.232 & .199 & $-21.59-$ & 3.44 \\
\hline \multirow[t]{2}{*}{ Repetition } & Glossing & $-18.495-^{*}$ & 5.449 & .003 & $-31.53-$ & $-5.46-$ \\
\hline & Gloss+Repetition & $-27.573-^{*}$ & 5.048 & .000 & $-39.65-$ & $-15.50-$ \\
\hline \multirow{2}{*}{$\begin{array}{l}\text { Gloss+Rep } \\
\text { etition }\end{array}$} & Glossing & 9.079 & 5.232 & .199 & $-3.44-$ & 21.59 \\
\hline & Repetition & $27.573^{*}$ & 5.048 & .000 & 15.50 & 39.65 \\
\hline
\end{tabular}

*. The mean difference is significant at the 0.05 level.

The above table draws a contrast of significance among the $G, R$ and $G+R$ treatment groups. By comparing the $\mathrm{G}$ group against the $\mathrm{R}$ group, it was found that the difference of the mean scores was statistically significant $(P=.003<.05)$. Likewise, such a significant difference in the mean scores was also found between the $\mathrm{G}+\mathrm{R}$ and $\mathrm{R}$ groups $(P=.000<.05)$. However, when comparing the $\mathrm{G}$ group against the $\mathrm{G}+\mathrm{R}$ group, the difference was found to be insignificant $(P=.199<.05)$. Such a result indicated that 
glossing alone was very effective and, that the addition of word repetition to glosses was not very necessary.

\section{DISCUSSION}

\section{The Effect of L1 Textual Glosses on Vocabulary Knowledge Acquisition}

As seen earlier, students showed a high level of performance on all immediate posttests based on their access to the L1 textual annotations provided for each of the treatment texts. They were able to score as high as $68 \%$ of all posttests, while their counterparts in the control group (who received no glossing) scored $46 \%$. Moreover, analysis by test type even yielded more promising results. The analysis showed that students in the L1 gloss (G) group were able to score on average 36.68 out of $40(92 \%)$ of the meaning tests, while their partners in the repetition (R) group (who did not receive any glosses) scored on average 16.8 out of $40(42 \%)$ on the meaning posttests. This entails that students who had access to L1 textual glosses were able to retain the meaning of the new words more effectively than their counterparts who have no glosses at all.

Therefore, this current study adds to the validity of the significance of glossing in learners' L1 as a reading intervention which leads to enhanced incidental acquisition. Such results suggest a robust correlation between the use of L1 textual glosses in reading texts and the learning of new vocabulary incidentally. Glossing items in learners' L1 was of much help to slightly alter learners' attention to the meaning of the new items. That, indeed, helped them establish a form-meaning relationship. Moreover, the reading activity was not interrupted by students either asking the teacher for the meaning of the new items or by referring to a dictionary to get the meaning.

\section{The Effect of Repetition on Vocabulary Knowledge Acquisition}

Evidently, students in the $\mathrm{CG}$ did not receive any single target word repetition as opposed to their counterparts in the $\mathrm{R}$ treatment group who received repetitions of the target items. The repetitions ranged from 2 to 6 exposures. This repetition intervention was effective since the participants who received target word repetitions were able to outperform their counterparts who received no repetition of the target items. Moreover, the difference in performance between the two groups was also significant by statistical conventions.

As seen earlier in the results, students who were provided with word frequency of occurrence were able to score on average 49.69 out of $100(50 \%)$ on all posttests, whilst their counterparts in the $\mathrm{CG}$ groups who received no target word repetitions scored as low as 35.19 out of $100(35 \%)$ on the same posttests. Further, the analysis by test type showed even a better output. Students in the R group scored on average $55 \%$ of the form and use posttests. This entails that when students were offered access to word repetition, they acquired both the structural and contextual aspects of word knowledge, as the researcher hypothesized.

However, the analysis of this study revealed an unexpected result. Despite the efficiency of word repetition, it was deemed significant only when students were not exposed to glossing. If they took word repetition on its own as a reading intervention, the effect will 
be apparent. In other words, the effect of word repetition was not deemed significant when learners were presented with textual glosses in their L1. Such a result indicates that the impact of L1 glosses is superior to that of word frequency of occurrence. This is justified on the evidence that students who did not receive target word repetition and received L1 glosses were also able to satisfactorily acquire the structural and contextual features of the target items. They scored on average 53\% of the form and use posttests, while students in the R group scored $55 \%$ of the same tests. The increase is not as high as it was expected, and the difference is not significant by statistical conventions as seen through the one way ANOVA results $(F(2.74)=2.267, P=.111>.05)$.

Another evidence of the superiority of L1 glosses over word repetition is found in the difference between the two treatment groups $(G$ and $G+R)$. The $G$ group received glosses only, while the $\mathrm{G}+\mathrm{R}$ group received both glosses and repetitions of the target items. It was assumed that if L1 glosses were accompanied by word repetition, students would acquire more aspects of word knowledge, since word repetition would foster the structural and contextual aspects. However, the analysis showed contradicting results to this hypothesis. Students in the G+R group who took glosses and repetition together scored on average $78 \%$ on all posttests, whilst the G group who received only L1 textual glosses scored $68 \%$ of the same tests. This difference, according to the one-way ANOVA analysis, was not considered significant.

Final evidence in favor of the impact of L1 textual glosses over word repetition is found in the performance of the $\mathrm{G}$ group and $\mathrm{R}$ group by test type. The $\mathrm{G}$ group was assigned to take the meaning tests, and the $\mathrm{R}$ group had to take the form and use tests. The performance of the $\mathrm{G}$ group was remarkably higher than the performance of the $\mathrm{R}$ group by test type. In other words, participants in the G group scored as high as $92 \%$ on the meaning tests, while their counterparts in the $\mathrm{R}$ group scored only $55 \%$ on the form and use tests. Obviously, students benefited from glosses as a reading intervention more than word repetition. If repetition was as highly effective as glosses, students would have performed better on the form and use tests.

\section{Pedagogical Implications for Teaching}

First, this study provides some insight into the importance of using L1 glosses and word repetition for vocabulary acquisition. It shows that offering access to textual glosses in learners' native language and repeating items several times can help students to pick up certain aspects of word knowledge starting from knowledge of meaning up to knowledge of use. This study also reveals that providing L1 glosses in texts is more facilitative for learning new L2 items than word repetition is. Students remarkably made an positive use of glosses reflected in their performance on the immediate posttests. This, however, does not entail that one has to put aside and ignore the effect of word repetition. If word repetition had a higher distribution across many texts, a case which was not fulfilled in this study, students may have had more benefit from merging glosses together with repetition. Therefore, realizing the benefits of L1 textual glosses and word repetition on acquiring new L2 items incidentally, it is intuitive that syllabus designers should produce new learning materials for students that include both variables. In case 
these interventions are not available, it is the role of teachers to incorporate them into their reading classes.

\section{CONCLUSION}

This study is an addition to the literature of glossing and repetition studies of L2 vocabulary acquisition. The aforementioned studies focused on either glossing (Hulstijn, 1992; Jacobs, Dufon and Fong, 1994; Watanabe, 1997; Yoshii, 2006; Al-Jabri, 2009) or word repetition (Saragi Nation and Meister, 1978; Horst et al, 1998; Nagy and Herman, 1987; Rott, 1999) per se. The exception was Hulstijn, Hollander and Greidanus's (1996) study who looked at both glosses together with repetition. This study, however, examined the effect of both L1 glosses and word repetition in reading texts on the incidental acquisition of new lexical items. It found that word repetition is indeed influential and can lead to the needed acquisition incidentally. In line with the Hulstijn et al (1996), more than a single exposure to the target items was needed to ensure that acquisition took place. Nevertheless, the number of repetitions is not reconciled. This study demonstrated that word repetition was unnecessary if another variable (L1 glosses) was presented together with word repetition. This is simply because the effect of L1 glosses was found to be superior to that of word repetition and that L1 glosses were more frequently accessed by students while they engaged in reading. When students had access to L1 textual glosses, they were able to satisfactorily acquire not only the knowledge of meaning of the target items but also the knowledge of form and use as well.

\section{RECOMMENDATIONS}

Further investigations are required to see how many repetitions are needed for incidental acquisition to take place. In this study, two to six repetitions were used. Further examination will be fruitful to determine the threshold of repetitions that can lead to acquisition. Moreover, despite the efficiency of L1 textual glosses on learning new lexical items, long-term retention of the acquisition of those aspects of knowledge (meaning, form, and use) should be taken into consideration. Only immediate posttests were given; delayed posttests are needed after some time to see to which extent glosses and repetition could help retain the aspects of knowledge. Another issue that can also be looked at is the effect of gender on the incidental acquisition. Only male students have been studied. Different results may have appeared if the study included females as well. Further, due to the limitation of time, only very few texts were selected for the experiment. If more time was available, more texts could have been involved; subsequently, many spaced repetitions could have been used across the different texts, which might have ultimately yielded different results in terms of the effect of word repetitions. In addition, in this study L1 textual glosses were studied. Because of learners' low proficiency level in English, L2 glosses were not considered. It was possible to investigate the effect of L1 as we as L2 glosses on word gains, and thus, determine language gloss could have been more facilitative for incidental acquisition. 


\section{REFERENCES}

AL-Jabri, S. (2009). The effects of L1 and L2 glosses on reading comprehension and recalling ideas by saudi students. Umm Al-Qura University J of Soc Sci, 1(1), 11-27.

Day, R. R., Omura, C., \& Hiramasu, M. (1991). Incidental EFL vocabulary learning and reading. Reading in a Foreign Language, 7(2), 541-551.

De Ridder, I. (2003). Reading from the screen in a second language: Empirical studies on the effect of marked hyperlinks on incidental vocabulary learning, text comprehension \& the reading process. Antwerp: Garant.

Ellis, R. (1999). Making the classroom acquisition-rich. In R. Ellis (Ed.), Learning a second language through interaction (pp. 211-229). Amsterdam: John Benjamins

Horst, M., Cobb, T., \& Meara, P. (1998). Beyond a clockwork orange: Acquiring second language vocabulary through reading. Reading in a Fore. Lan., 11(2), 207-223.

Hulstijn, J. (1992). Retention of inferred and given word meanings: Experiments in incidental vocabulary learning. In P. J. L. Arnaud, \& H. Bejoint (Eds.), Vocabulary and Applied Linguistics (pp. 113-125). London: Macmillan.

Hulstijn, J. H. (2003). Incidental and intentional learning. In C. Doughty, \& M. H. Long (Eds.), The handbook of second language acquisition (pp. 349-381). Oxford: Blackwell.

Hulstijn, J. H., Hollander, M., \& Greidanus, T. (1996). Incidental vocabulary learning by advanced foreign language students: the influence of marginal glosses, dictionary use, \& reoccurrence of unknown words. The Modern Language Journal, 80, 327-339.

Jacobs, G. M., Dufon, P., \& Hong, F. C. (1994). L1 and L2 vocabulary glosses in L2 reading passages: Their effectiveness for increasing comprehension and vocabulary knowledge. Journal of Research in Reading, 17(1), 19-28.

Karp, A. S. (2002). Modification of glosses and its effect on incidental L2 vocabulary learning in Spanish (Unpublished doctoral dissertation). University of California.

Krashen, S. (1989). We acquire vocabulary and spelling by reading: Additional evidence for the input hypothesis. The Modern Language Journal, 73(4), 440-464.

Meara, P. (1980). Vocabulary acquisition: A neglected aspect of language learning. Language teaching, 13(3-4), 221-246.

Nagy, W. E., \& Herman P.A. (1987). Breadth and depth of vocabulary knowledge: Implications for acquisition and instruction. In M. McKeownand, \& Curtis, M. (Eds.), The nature of vocabulary acquisition (pp.19-35). Hillsdale, NJ: Erlbaum.

Nagy, W. E., Herman, P. A., \& Anderson, R. C. (1985). Learning words from context. Reading Research Quarterly, 20(2), 233-253. 
Nation, I. S. P. (2001). Learning vocabulary in another language (Cambridge Applied Linguistics). Cambridge: Cambridge University Press.

Paribakht, T. S., \& Wesche, M. (1999). Reading and "incidental" L2 vocabulary acquisition: An introspective study of lexical inferencing. Studies in Second Language Acquisition, 21(1), 195-224.

Pitts, M., White, H., \& Krashen, S. (1989). Acquiring second language vocabulary through reading: A replication of the clockwork orange study using second language acquirers. Reading in a Foreign Language, 5(2), 271-275.

Read, J. (1993). The development of a new measure of L2 vocabulary knowledge. Language Testing, 10(3), 355-371.

Read, J. (2000). Assessing vocabulary. Cambridge: Cambridge University Press.

Read, J. (2004). Research in teaching vocabulary. An. Rev. of App. Lin., 24(1), 146-161.

Rott, S. (1999). The effect of exposure frequency on intermediate language learners' incidental vocabulary acquisition through reading. Studies in Second Language Acquisition, 21(4), 589-619.

Rott, S. (2005). Processing glosses: A qualitative exploration of how form-meaning connections are established and strengthened. Reading in a Foreign Lan., 17(95-124).

Rott, S., Williams, J., \& Cameron, R. (2002). The effect of multiple-choice L1 glosses and input-output cycles on lexical acquisition and retention. Language Teaching Research, 6(3), 183-222.

Saragi, T., Nation, I. S. P., \& Meister, G. F. (1978). Vocabulary learning and reading. System, 6(2), 72-78.

Watanabe, Y. (1997). Input, intake and retention. The Modern Lan. J, 19(3), 287-307.

Zahar, R., Cobb, T., \& Spada, N. (2001). Acquiring vocabulary through reading: effects of frequency and contextual richness. Canadian Modern Lang. Review, 57(4), 541-572.

Al Shabab, O. S. (2012, April). First person domain: threshold mental lexicon and Arab learners of English. Proceedings of the Second Symposium on English Language Teaching in KSA: Realities and Challenges (pp.141-208). Riyadh.

Al-Shiekh Mubarak, G. (2009). Vocabulary range and frequency in first intermediate girls' English textbook in Saudi Arabia: learners' achievement and strategies (Unpublished master thesis). King Faisal University.

Nation, I. S. P. (2006). How large a vocabulary is needed for reading and listening? The Canadian Modern Language Review, 36(1), 59-82

Thorndike, E. L. (1908). Memory for paired associates. Psycholog. Rev, 15(2), 122-138. 
Siebert, L. C. (1930). An experiment on the relative efficiency of studying French vocabulary in associated pairs versus studying French vocabulary in context. Journal of Educational Psychology, 21, 297-314. 